\title{
Sulfonated Polymethylsiloxane as an Additive for Selective Calcium Oxalate Crystallization
}

\author{
Andrónico Neira-Carrillo, ${ }^{*[a]}$ Fabian Luengo-Ponce, ${ }^{[a]}$ \\ Patricio Vásquez-Quitral, ${ }^{[a]}$ Mehrdad Yazdani-Pedram, ${ }^{[b]}$ \\ María Soledad Fernández, ${ }^{[a]}$ Helmut Cölfen, ${ }^{[c]}$ and José Luis Arias ${ }^{[a]}$
}

Keywords: Sulfonated polymethylsiloxane / Template synthesis / Urolithiasis / Calcium oxalate / Calcium / Crystal growth

Sulfonated and fluorescent polymethylsiloxanes $\left(\mathrm{SO}_{3} \mathrm{H}-\right.$ PMS) were synthesized, and their effect as additives on in vitro calcium oxalate $(\mathrm{CaOx})$ crystallization was evaluated. $\mathrm{SO}_{3} \mathrm{H}-\mathrm{PMS}$ was prepared by hydrosilylation and sulfonation reactions with poly(dimethylsiloxane-co-hydrogenmethylsiloxane) (PDMS-co-PMHS). Several analytical tools were used to investigate the morphology, crystal structure, and chemical contents of the harvested CaOx crystals. Varying the concentration of $\mathrm{SO}_{3} \mathrm{H}-\mathrm{PMS}$ induces a transition of $\mathrm{CaOx}$ monohydrate (COM) with expanded multilayer and circular

\section{Introduction}

Kidney-stone affliction (Urolithiasis) is prevalent worldwide and affects about $10 \%$ of the population in developed countries. Methods of preventing this condition have been investigated. ${ }^{[1,2]}$ In healthy people, the presence of specific micro- and macromolecules inhibits the formation of calcium oxalate monohydrate (COM) and promotes the formation of healthy calcium oxalate dihydrate (COD) crystals. Urolithiasis is complex, because there are many variables controlling the nucleation and crystal growth of calcium oxalate $(\mathrm{CaOx})$. Among these variables are supersaturation, organic components in the urine, crystal interactions with the kidney epithelium, and kinetic factors, which include nucleation, growth, and aggregation. ${ }^{[3]}$ Supersaturation of oxalate and calcium ions in the urine may cause the formation of crystalline particles, which can be excreted freely. The retention of these crystals may result in kidney stones, which comprise both inorganic and organic compo-

[a] Biological and Animal Sciences, University of Chile,

Santa Rosa 11735, P. O. Box 2-15, Santiago, Chile

E-mail: aneira@uchile.cl

http://www.veterinaria.uchile.cl/?_nfpb=true\&_pageLabel= conUrlVeterinaria\&url $=66658$

[b] Department of Organic and Physical Chemistry, University of Chile,

Sergio Livingstone 1007, P. O. Box 233, Independencia,

Santiago, Chile

[c] Physical Chemistry, Department of Chemistry, University of Konstanz,

Box 714, 78457 Konstanz, Germany stacked-sheet morphologies as well as of the bipyramidal $\mathrm{CaOx}$ dihydrate (COD) crystals in three crystallization procedures. Energy-dispersive X-ray spectroscopy (EDS) and XRD allowed detecting the presence of $\mathrm{Si}\left(0.2-1.0^{\circ} \mathrm{wt} . \mathrm{\%}\right)$, which stems from $\mathrm{SO}_{3} \mathrm{H}$-PMS adsorbed on $\mathrm{CaOx}$, and the selective formation of phases of COM and COD. We demonstrated that the presence of anionic moieties on the $\mathrm{SO}_{3} \mathrm{H}$ PMS backbone and their concentration were crucial to control the crystal type, morphology, crystal size, and chemical composition.

nents. The organic part is composed of urinary macromolecules, for example, proteins, lipids, and carbohydrates. ${ }^{[4]}$

It is well known that $\mathrm{CaOx}$ exists as mono-, di-, and trihydrate polymorphs. ${ }^{[5,6]}$ The monohydrate form is the thermodynamically most stable one and has the strongest affinity for renal tubular cell membranes. Sulfated polysaccharides prevent the adhesion of COM crystals to renal epithelial cells. ${ }^{[7,8]} \mathrm{A}$ direct evidence for the above proposition is that stone-forming subjects, both adults and children, excrete lower levels of glycosaminoglycans (GAGs). ${ }^{[9,10]}$ Chondroitin $4 / 6$ sulfate (CS), the most abundant urinary glycosaminoglycan, ${ }^{[1-13]}$ inhibits in vitro the growth of $\mathrm{CaOx}$ crystals in urine. ${ }^{[1,14]}$ In contrast, in vivo studies showed that intraperitoneal administration of CS promoted an increase rather than a decrease in the weight of bladder stones in rats, because CS was extensively degraded prior to urinary excretion. ${ }^{[15]}$

Therefore, the understanding of the interactions between kidney stone crystals and the organic component is of the greatest interest for controlling the crystallization of $\mathrm{CaOx} .{ }^{[16,17]}$ The effect of polyanions containing acidic groups (e.g., carboxylate, sulfate, and phosphate) on the crystallization process may be explained by the following mechanisms: (a) polymers may change the ionic strength of the solution, (b) polymers can form stable coordinative links with calcium ions, (c) the adsorption of polymer occurs in an indiscriminate or selective way on specific sites of the crystal surface, and (d) the polymer incorporation occurs inside the $\mathrm{CaOx}$ lattice. ${ }^{[18]}$ Many studies on $\mathrm{CaOx}$ crystallization have used organic molecules either as addi- 
tives or substrates. ${ }^{[19-29]}$ Anionic macromolecules could inhibit the nucleation, growth, and aggregation of $\mathrm{CaOx}$ crystals, and they are involved in the in vitro cell-crystal attachment. ${ }^{[24]}$ Some other authors have examined inorganic polymers as additives. ${ }^{[30,31]}$

On the other hand, polymethylsiloxanes are the most important and widely used silicon-based organic polymers, which are biocompatible, biodegradable, non-carcinogenic, and offer a convenient cost-benefit ratio. ${ }^{[32]}$ Polymethylsiloxanes functionalized with anionic groups, such as $-\mathrm{CO}_{2} \mathrm{H},-\mathrm{SO}_{3} \mathrm{H}$, and $-\mathrm{PO}_{3} \mathrm{H}$, would favor the formation of COD. In fact, we have previously synthesized and functionalized a polymethylsiloxane with carboxylic groups, which was able to promote the stabilization of COD in detriment of COM crystals. ${ }^{[33]}$ Herein, we have synthesized a sulfonated polymethylsiloxane ( $\left.\mathrm{SO}_{3} \mathrm{H}-\mathrm{PMS}\right)$ and evaluated its effect as a modifier of $\mathrm{CaOx}$ by using different in vitro crystallization procedures.

\section{Results and Discussion}

\section{Synthesis of Sulfonated Polymethylsiloxane ( $\left.\mathrm{SO}_{3} \mathrm{H}-\mathrm{PMS}\right)$ as a Template}

The preparation of $\mathrm{SO}_{3} \mathrm{H}-\mathrm{PMS}$ (5), which was used as an additive for the in vitro crystallization of $\mathrm{CaOx}$, involved two stages (Figure 1). The starting copolymer poly(dimethylsiloxane-co-hydrogenmethylsiloxane) (1, PDMS-coPMHS) copolymer was synthesized through cationic ringopening polymerization at $30{ }^{\circ} \mathrm{C}$ for $5 \mathrm{~d}$ by using siloxane as a cyclic monomer. The starting compound $\mathbf{1}$ was modified through the hydrosilylation reaction and subsequent sulfonation, which afforded 5. Figure 1a shows the synthesis of modified 1 with styrene (2), which affords Styr-PMS (3) through the hydrosilylation reaction; $\mathbf{3}$ was modified with a stoichiometric amount of sulfonic groups of sulfuric acid (4) by dissolving 3 in dichloromethane at room temperature overnight, after which the reaction temperature was increased to $80{ }^{\circ} \mathrm{C}$, and the reaction mixture was incubated for $2 \mathrm{~h}$.

\section{In Vitro Calcium Oxalate Crystallization Experiments}

The crystallization was performed by using three procedures: A, B, and $\mathrm{C}$. They differ by the nature of the reagents used, that is, $\mathrm{CaCl}_{2}$ or $\mathrm{Ca}\left(\mathrm{NO}_{3}\right)_{2} \cdot 4 \mathrm{H}_{2} \mathrm{O}$ in combination with $\mathrm{Na}_{2} \mathrm{C}_{2} \mathrm{O}_{4}$, the $\mathrm{Ca}$ /oxalate ratio, and the concentration of $\mathbf{5}$ (Table 1). The aim of the procedures A and B was to evaluate the morphogenetic effect of $\mathbf{5}$ on the crystal growth of $\mathrm{CaOx}$, whereas procedure $\mathrm{C}$ was aimed at demonstrating the adsorption capacity of fluorescent $\mathbf{5}$ onto the $\mathrm{CaOx}$ crystal surface. The reactants were $\mathrm{CaCl}_{2}$ and $\mathrm{Na}_{2} \mathrm{C}_{2} \mathrm{O}_{4}$ for procedure $\mathrm{A}$ and $\mathrm{Ca}\left(\mathrm{NO}_{3}\right)_{2} \cdot 4 \mathrm{H}_{2} \mathrm{O}$ and $\mathrm{Na}_{2} \mathrm{C}_{2} \mathrm{O}_{4}$ for procedure $\mathrm{B}$. In procedure $\mathrm{A}, \mathrm{CaCl}_{2}$ is often used to evaluate the nucleation and crystal growth of $\mathrm{CaOx}$ in cases where low $\mathrm{Ca}$ ion concentration is required. In procedure $\mathrm{B}, \mathrm{Ca}\left(\mathrm{NO}_{3}\right)_{2} \cdot 4 \mathrm{H}_{2} \mathrm{O}$ was utilized as a $\mathrm{Ca}$ source to yield a large amount of crystals for XRD and fluorescence analysis. Both compounds allowed us to provide high ion and additive concentrations for $\mathrm{CaOx}$ crystallization (see
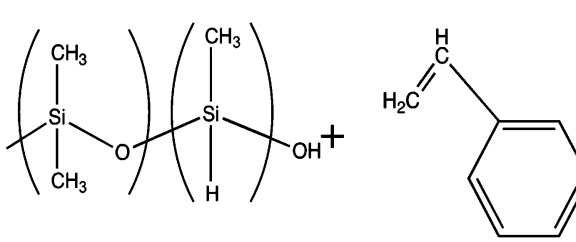

1

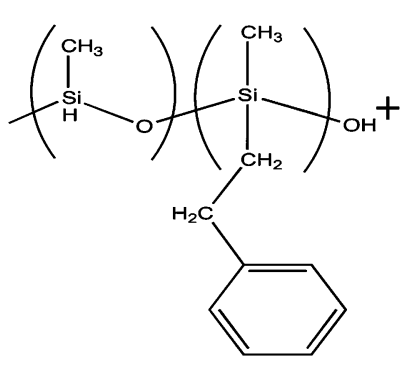

$\mathrm{HO}-\|_{0}^{\mathrm{O}}-\mathrm{OH}$

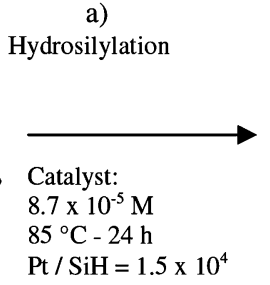

$\mathrm{Pt} / \mathrm{SiH}=1.5 \times 10^{4}$

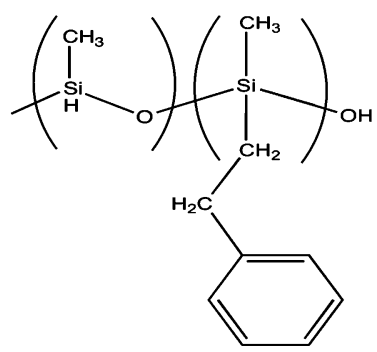

3

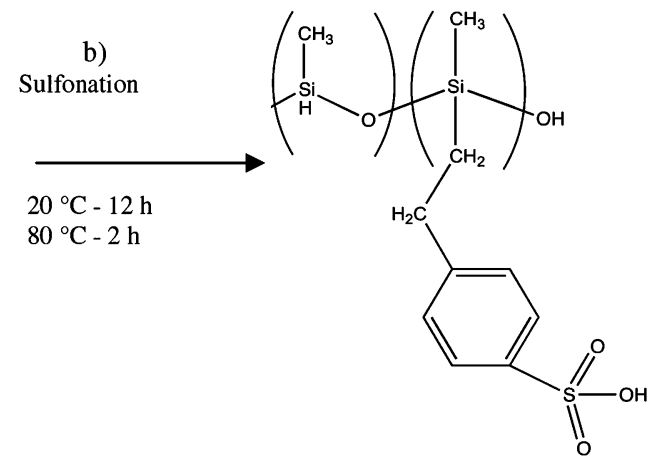

Figure 1. Synthesis of 5 through (a) hydrosilylation and (b) sulfonation. 
Table 1. In vitro crystallization procedures of calcium oxalate.

\begin{tabular}{cccc}
\hline Reagents & Procedure A & Procedure B & Procedure C \\
\hline $\mathrm{CaCl}_{2}{ }^{[\mathrm{a}]}$ & 2.0 & - & 5.0 \\
$\mathrm{Ca}\left(\mathrm{NO}_{3}\right)_{2}{ }^{[a]}$ & - & 2.0 & - \\
$\mathrm{Na}_{2} \mathrm{C}_{2} \mathrm{O}_{4}{ }^{[a]}$ & 2.0 & 2.0 & 0.5 \\
$\mathrm{Ca} \mathrm{Ox} \mathrm{ratio}_{\mathrm{SO}} \mathrm{H}_{-} \mathrm{PMS}^{[\mathrm{b}]}$ & $1: 1$ & $1: 1$ & $10: 1$ \\
Fluorescent SO$_{3} \mathrm{H}_{-} \mathrm{PMS}^{[\mathrm{b}]}$ & $640,64,6.4,0.64$ & $1000,500,100$ & $470,160,47,16$ \\
\hline
\end{tabular}

[a] Concentrations of reagents given in mmol/L. [b] Concentrations of reagents given in $\mathrm{mg} / \mathrm{L}$.

Experimental Section). Similar crystallization conditions with both $\mathrm{Ca}$ sources have been reported by B. Grohe et al. ${ }^{[34,35]}$

\section{Characterization of Polymers}

The polydispersity ( $\left.\chi^{\circ}{ }^{\circ}\right)$ and molecular weight of 1 were 0.5 and $16349 \mathrm{~g} / \mathrm{mol}$, respectively. The structures of all polymers were confirmed by FTIR spectroscopy (Figure 2). The absence of the absorption band at $2160 \mathrm{~cm}^{-1}$ in 3 (Figure $2 \mathrm{~b}$ ), which is attributed to $\mathrm{Si}-\mathrm{H}$ stretching vibrations (Figure 2a), confirms the successful hydrosilylation of $\mathbf{1}$. The sulfonation of $\mathbf{3}$ was confirmed by the presence of absorption bands characteristic of the $\mathrm{SO}_{3} \mathrm{H}$ groups at 1040 and $1180 \mathrm{~cm}^{-1}$ in the spectrum of 5 (Figure 2c). ${ }^{[36]}$ Absorption bands at 1100 and $1300 \mathrm{~cm}^{-1}$ also confirmed the presence of sulfonic groups bound to the aromatic ring in $\mathbf{5}$. Moreover, the quantitative presence of $\mathrm{Si}$ and $\mathrm{S}$ atoms in $\mathbf{5}$, determined by energy-dispersive X-ray spectroscopy (EDS), was in the concentration range of 3.0-10.9 and 2.0-2.5 wt.$\%$, respectively.

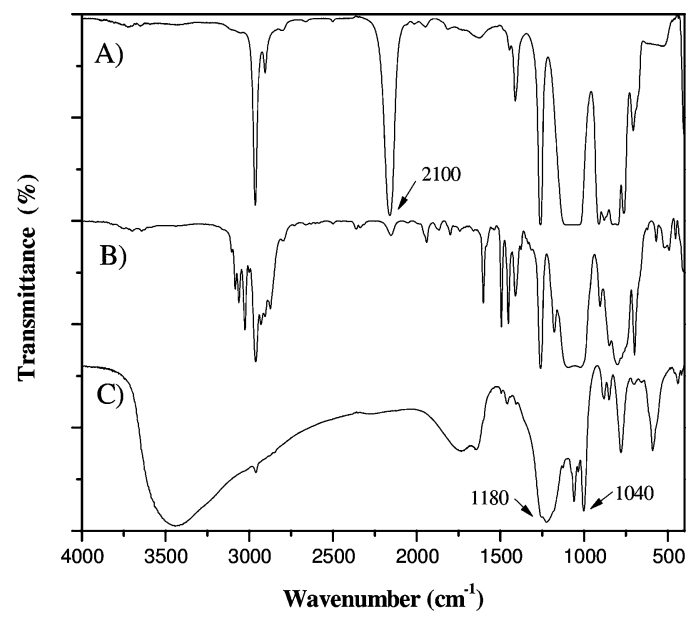

Figure 2. FTIR spectra of (a) 1, (b) 3, and (c) 5 .

\section{Characterization of $\mathrm{CaOx}$ Crystals}

Table 1 shows the experimental conditions used for the crystal growth of $\mathrm{CaOx}$ with varying ratios of $\mathrm{Ca}$ /oxalate ions and varying amounts of sulfonated and fluorescent 5 as an additive. The results of scanning electron microscopy (SEM) and X-ray diffraction (XRD) for $\mathrm{CaOx}$ crystals obtained in the presence of $640 \mathrm{mg} / \mathrm{L}$ of 5 with procedure A at $20^{\circ} \mathrm{C}$ for $24 \mathrm{~h}$ are shown in Figure 3. The SEM analyses of $\mathrm{CaOx}$ formed in the absence of $\mathbf{5}$ (Figure $3 \mathrm{a}$ ) showed branched-stacked COM. These crystals show edges with a "hacksaw" shape $(20-30 \mu \mathrm{m})$. However, when $\mathbf{5}$ was used as an additive, the crystals formed were coincident with at least two polymorphs, which are clearly detectable. The first crystal type corresponds to a bipyramidal crystal $(30 \mu \mathrm{m})$ and has right edges, which correspond to the morphological characteristics described for COD (Figure 3b). The second crystal type corresponds to dumbbell-shaped COM, exhibiting two poles with curves and edges with pores, which are separated by a regular and deep central groove $(5-8 \mu \mathrm{m})$ (Figure 3c). Wesson et al. ${ }^{[37]}$ obtained COM crystals in the presence of polyglutamic acid (poly-Glu), which were similar in shape but smaller in size. A morphology similar to the one we obtained with $640 \mathrm{mg} / \mathrm{L}$ of 5 was obtained by Taller et al. ${ }^{[3]}$ by adding $5 \times 10^{-3}$ to $15 \times 10^{-3} \mathrm{mg}$ of osteopontin (OPN), a protein abundant in urine, at low supersaturation, that is, a $\mathrm{Ca} /$ oxalate ratio of 1 . OPN induced the formation of dumbbell-shaped crystals with roughened surfaces and rounded edges, which lacked plane faces and interfacial angles. Viewed from the $\{100\}$ direction, these crystals were oval in cross section with an oval depression on the $\{100\}$ face. The depressions were also visible in crystals viewed from the $\{010\}$ direction. The striking similarities between dumbbell-shaped COM crystals induced by $\mathbf{5}$ and modified COM crystals formed under the influence of OPN suggest that polymer $\mathbf{5}$ may modify the $\mathrm{CaOx}$ type in a similar manner as this natural inhibitor ${ }^{[37]}$ On the other hand, when no additive was used, the results of the XRD analysis showed a typical pattern characteristic for COM (Figure 3d). Diffraction peaks of COM crystals appear at $2 \theta$ values of $14.92^{\circ}$ for reflection $(-101)$, at $24.37^{\circ}$ for reflection $(020)$, at $30.11^{\circ}$ for reflection $(-202)$, and at $38.18^{\circ}$ for reflection (130). However, when 5 was added at a concentration of $640 \mathrm{mg} / \mathrm{L}$ (Figure 3e) together with COM, new diffraction peaks appeared at $2 \theta$ values of $14.32^{\circ}$ for reflection (200), at $20.07^{\circ}$ for reflection (211), and at $32.24^{\circ}$ for reflection (411), which correspond to the presence of COD crystals. This XRD observation was supported by the presence of bipyramidal crystals observed by SEM. With this evidence, we suggest that the dumbbell-shaped crystals correspond to COM. Morphology and size of these crystals are similar to those found in previous works, where the ef- 


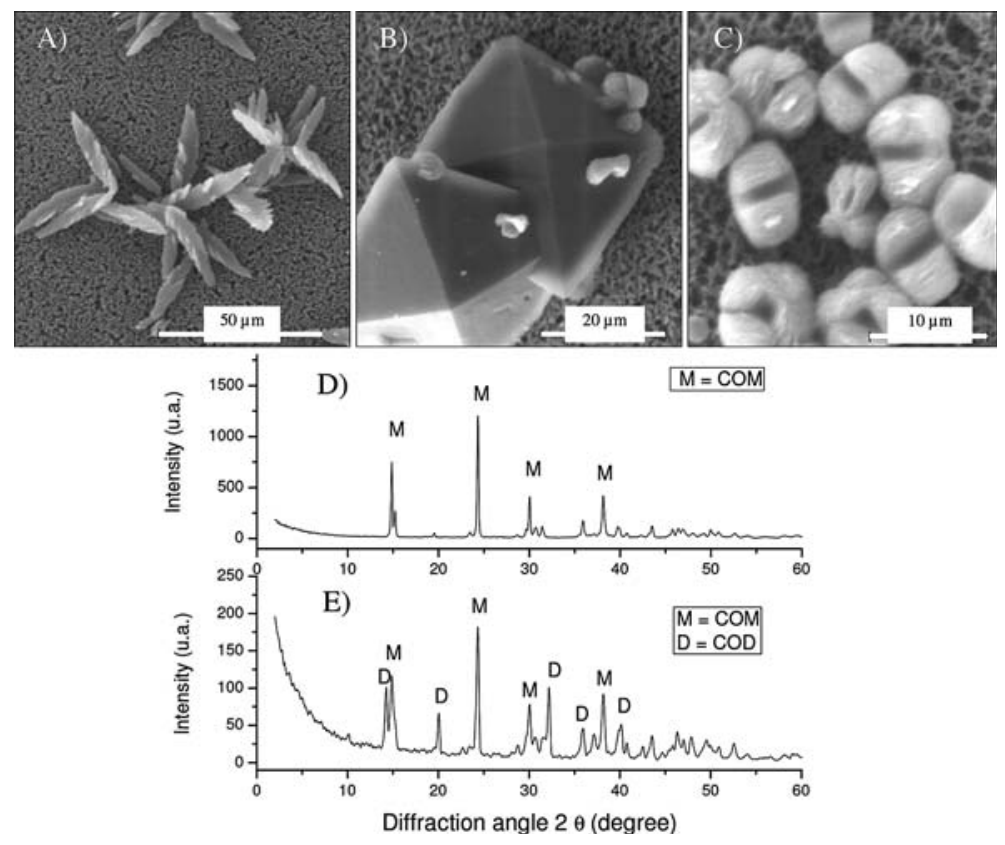

Figure 3. SEM and XRD measurements of $\mathrm{CaOx}$ crystals obtained in the presence of $640 \mathrm{mg} / \mathrm{L}$ of 5 with procedure $\mathrm{A}\left(\mathrm{CaCl} \mathrm{C}_{2}\right.$ and $\mathrm{Na}_{2} \mathrm{C}_{2} \mathrm{O}_{4}$ at $20^{\circ} \mathrm{C}$ for $24 \mathrm{~h}$ ). SEM image of $\mathrm{CaOx}$ (a) without additive and (b, c) with 5 . XRD pattern of CaOx of (d) a control sample and (e) a sample obtained with $\mathbf{5}$.

fect of natural urinary inhibitors on the CaOx crystallization was evaluated. ${ }^{[38]}$

With procedure $\mathrm{B}, \mathrm{CaOx}$ crystals were obtained in the presence of $100-1000 \mathrm{mg} / \mathrm{L} \mathrm{SO}_{3} \mathrm{H}-\mathrm{PMS}$ by using $\mathrm{Ca}-$ $\left(\mathrm{NO}_{3}\right)_{2} \cdot 4 \mathrm{H}_{2} \mathrm{O}$ and $\mathrm{Na}_{2} \mathrm{C}_{2} \mathrm{O}_{4}$ as reactants at $37^{\circ} \mathrm{C}$ for $24 \mathrm{~h}$, and they were also analyzed by SEM-EDS (Figure 4). The SEM images of $\mathrm{CaOx}$ formed in the absence of 5 (Figure 4a) showed the typical COM morphology, which consists of well-faceted monoclinic penetration twins with developed $\{010\},\{100\}$, and $\{121\}$ faces. The flat $\{100\}$ and $\{010\}$ faces show a smooth and a porous, spiky surface, respectively. The size of the COM crystals was distributed homogeneously and in the range of approximately $20 \mu \mathrm{m}$. At low concentration, in the range of $100 \mathrm{mg} / \mathrm{L}$ (Figure 4b), 5 induced the transition of COM crystals with expanded multilayers, round edges, and wide concave surface morphologies, which still express $\{100\}$ faces. At this concentration, the morphology of COM crystals slightly changed and exhibited the above-described faces, but they lost their welldefined spiky surface. The sizes of these modified COM crystals were distributed heterogeneously and appeared in the range $20-100 \mu \mathrm{m}$. However, when $\mathbf{5}$ was used at a concentration of $500 \mathrm{mg} / \mathrm{L}$, both COM and COD clearly formed (Figure 4c). The COM crystals showed a rough surface described as stacked sheets, which may correspond to the $\{010\}$ and $\{121\}$ faces, whereas the $\{100\}$ face is folded on itself by the expanding effect of the $\{010\}$ face. The second COD polymorph was bipyramidal (Figure 4c) with the $\{011\}$ face. The distribution of the crystal size was heterogeneous $(20-60 \mu \mathrm{m})$. With $1000 \mathrm{mg} / \mathrm{L}$ of $\mathbf{5}$, the sulfonic acid moieties showed a strong and regular effect on the $\mathrm{CaOx}$ crystal type. COM crystals formed in characteristic multilayers and circular stacked-sheet shapes (Figure 4d).
The concentrations of $\mathbf{5}$ in procedure B were higher than that of natural biomolecules because of the chemical nature, molecular weight, and low functionalization degree of synthetic additive $\mathbf{5}$ compared to urinary biomolecules. A high concentration was used to visualize the major modifying effect of $\mathbf{5}$ on the $\mathrm{CaOx}$ morphology and crystal type. XRD patterns (Figure 4e) of crystals obtained with protocol B only show the COM pattern in all samples, and only the relative intensities of the peaks differ. Reflection (020) was proportionally lower with respect to the other peaks, compared with the control. Most of the high- and low-molecular-weight inhibitors present in urine, which likely interact with specific regions of the $\mathrm{CaOx}$ crystals, are polyanionic. The (100) faces of COM are rich in $\mathrm{Ca}^{2+}$. Thus, negatively charged molecules may interact strongly with the $\mathrm{Ca}^{2+}$ ions densely packed inside the (100) face through electrostatic interactions, thereby blocking the COM growth. ${ }^{[39]}$ However, not all faces have the same elemental distribution. The (121) face has less $\mathrm{Ca}^{2+}$ than the (100) face, whereas the (010) face exhibits a high quantity of oxalate ions on the surface compared to the (100) and (121) faces. ${ }^{[35]}$ Thus, negatively charged molecules interact with these faces to a lesser extent, allowing less restriction of the crystal growth on these sites. We suggest that the selective adsorption of $\mathbf{5}$ on the $\{100\}$ faces decreases the growth rate on these sites, whereas the $\{010\}$ faces form with less restriction. These different expansion rates cause the opposed $\{010\}$ faces to bind on the $\{100\} /\{010\}$ edges, which accordingly invade the $\{100\}$ faces, which fold over themselves. The distribution of both ions in the crystal lattice and the resulting specific charge expression on each side of the crystal surface could explain the alteration of the COM morphology obtained in our crystallization assays. The magnitude of the 


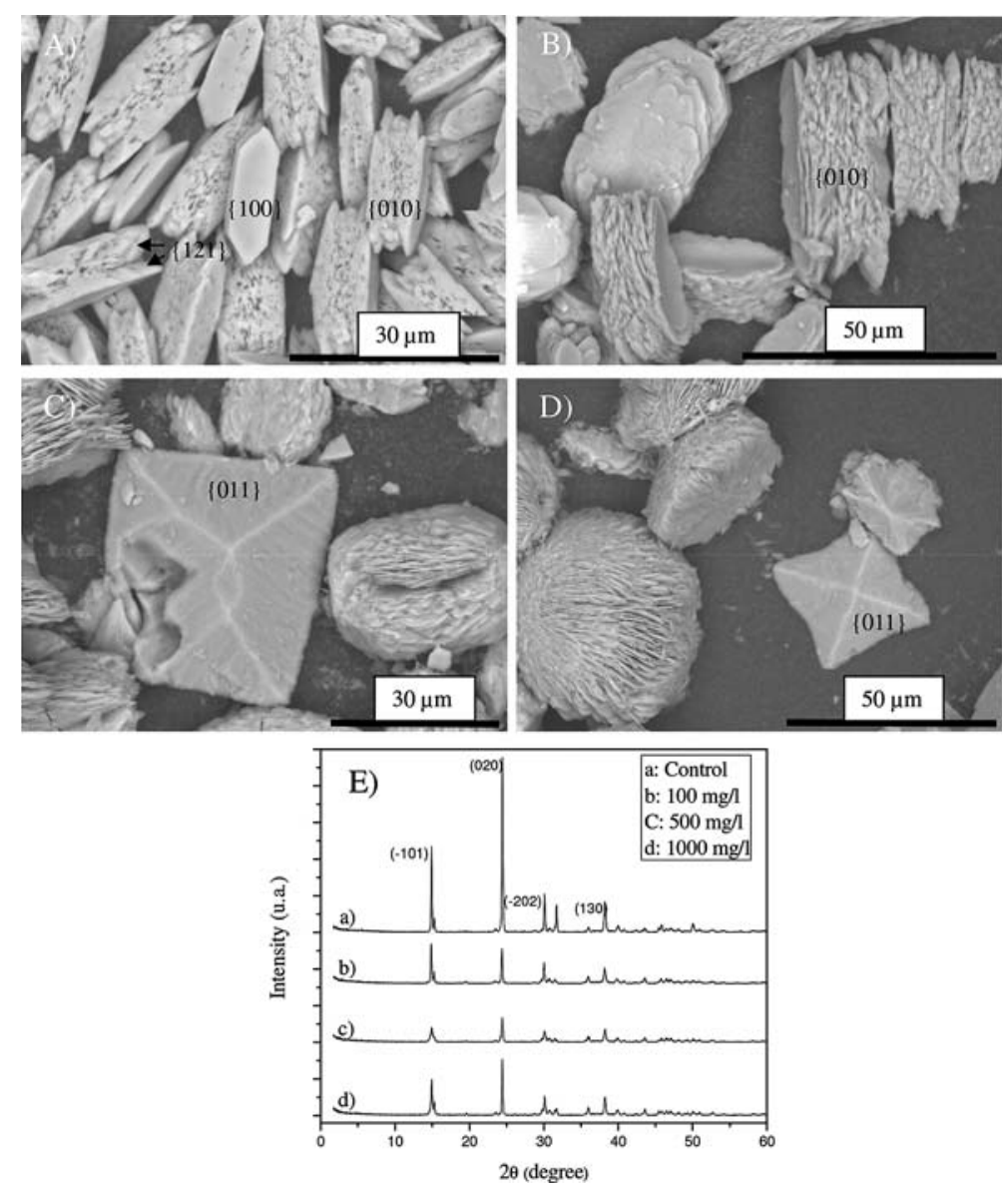

Figure 4. SEM and XRD measurements of crystals obtained in the presence of 5 with procedure $\mathrm{A}\left[\mathrm{Ca}\left(\mathrm{NO}_{3}\right)_{2} \cdot 4 \mathrm{H}_{2} \mathrm{O}\right.$ and $\mathrm{Na}_{2} \mathrm{C}_{2} \mathrm{O}_{4}$ at $37^{\circ} \mathrm{C}$ for $24 \mathrm{~h}$ ]. SEM images of $\mathrm{CaOx}$ crystals obtained with (a) 0 (control), (b) 100, (c) 500, and (d) $1000 \mathrm{mg} / \mathrm{L}$ of 5 .

alteration of each face results in a circular structure with a stacked-sheets surface corresponding to the $\{010\}$ face and flat corresponding to the $\{121\}$ faces. On the other hand, COD crystals showed a starfish shape similar to those observed by Jung et al., ${ }^{[40]}$ who used $8 \times 10^{-3} \mathrm{mg} / \mathrm{mL}$ of polyL-aspartate (poly D) as an additive. The crystal-size distribution was variable and appeared in the range 30-70 $\mu \mathrm{m}$. This can be explained by considering that the (011) and (010) faces in COD crystals include water molecules in high concentration, which alternate with layers of pure water and thereby greatly reduce the ionic charge of the crystal surface. Hence, COD crystals interact to a lesser extent with negatively charged urinary molecules, promoting the formation of these in the urine. ${ }^{[39]}$ In this regard, our assays suggest that higher concentrations of $\mathbf{5}$ promote the formation of COD crystals with minimal change in the typical morphology of these particles.

Because the inhibition of the $\mathrm{CaOx}$ nucleation is related to adsorption phenomena, the total amount of polymer adsorbed and the degree of surface coverage of the adsorbate on the inorganic crystal are important factors in determining the level of effectiveness of the polymer additive. ${ }^{[41]}$ Energy-dispersive X-ray spectroscopy (EDS) measurements were performed on the surface of washed and dried $\mathrm{CaOx}$ crystals obtained with protocol A (Figure 5), as a qualitative technique, to determine the presence of adsorbed $\mathbf{5}$. Despite the strong effect of $\mathbf{5}$ on the $\mathrm{CaOx}$ morphology, which was revealed by SEM, EDS did not allow to detect the presence of $\mathrm{Si}$ adsorbed on the COM surface when 5 was used at a concentration of $100 \mathrm{mg} / \mathrm{L}$ (Figure 5b). Also, the ratio of $\mathrm{Ca}, \mathrm{C}$, and $\mathrm{O}$ atoms detected on the COM was in good agreement with the theoretical value of pure $\mathrm{CaOx}$. Nevertheless, when $\mathbf{5}$ was used at concentrations of 500 and $1000 \mathrm{mg} / \mathrm{L}$ (Figure 5c-f), EDS data showed the presence of $\mathrm{Si}$ from $\mathbf{5}$ on the COM and COD surfaces. In this case, the experimental values of $\mathrm{Ca}, \mathrm{C}$, and $\mathrm{O}$ content differ from the theoretical values, and the presence of other elements was detected, which indicates that the amount of adsorbed polymer varied considerably between the described faces. However, the results of the EDS measurements clearly demonstrate the presence of $\mathrm{Ca}$ and $\mathrm{Si}$ atoms on the $\mathrm{CaOx}$ crystal surface. EDS data show that the presence of Si atoms becomes apparent when $\mathbf{5}$ is used in a concentration of $500 \mathrm{mg} / \mathrm{L}$ (Figures $5 \mathrm{c}$ and $\mathrm{d}$ ). The $\mathrm{Ca} / \mathrm{Si}$ ratio in the surface of COM crystals was 36.68 and 20.5 for 500 and $1000 \mathrm{mg} /$ $\mathrm{L}$ of $\mathbf{5}$, respectively. Therefore, the presence of $\mathrm{Si}$ atoms on 

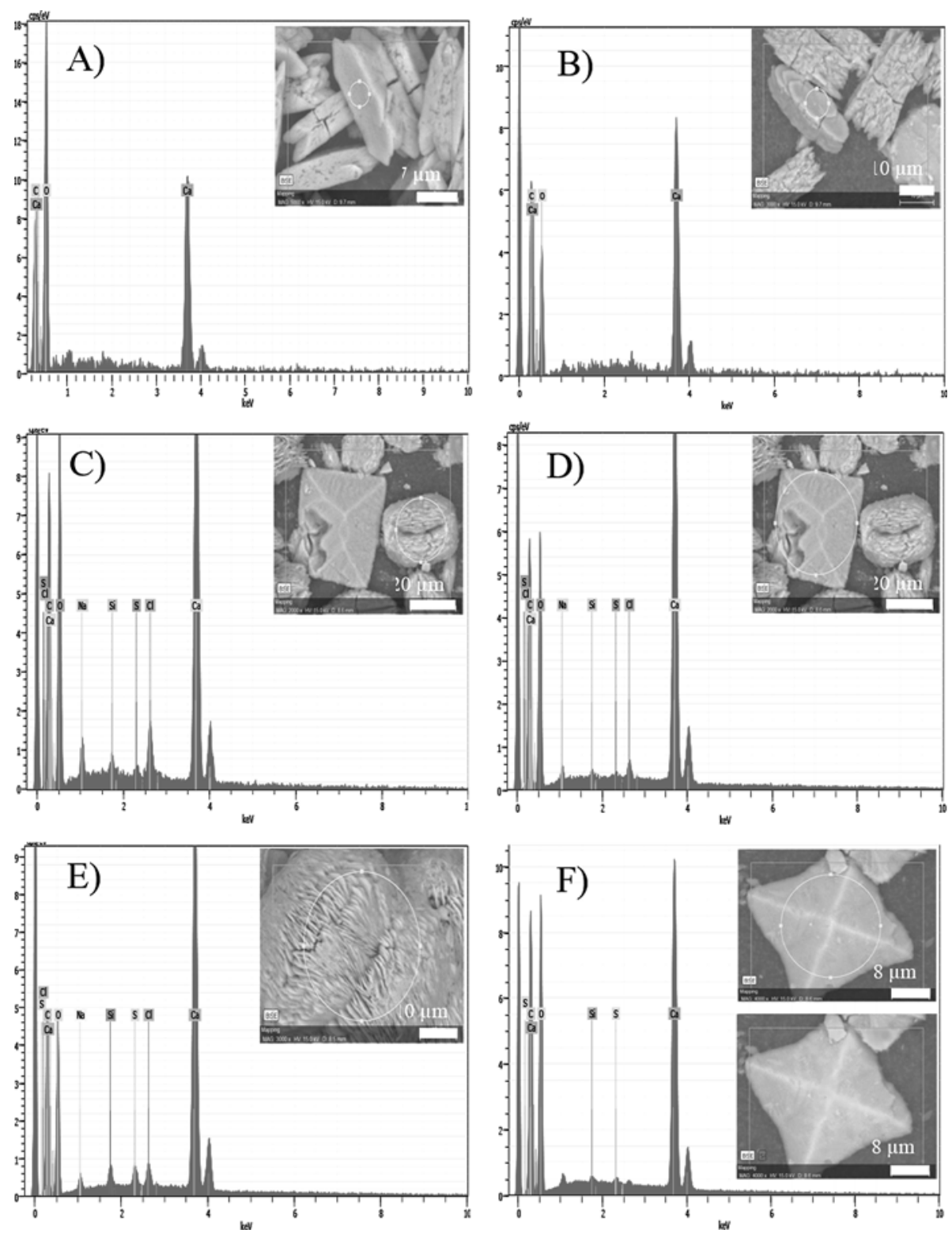

Figure 5. SEM-EDS measurements of $\mathrm{CaOx}$ crystals obtained in the presence of 5 with procedure $\mathrm{A}\left[\mathrm{Ca}\left(\mathrm{NO}_{3}\right)_{2} \cdot 4 \mathrm{H}_{2} \mathrm{O}\right.$ and sodium oxalate at $37^{\circ} \mathrm{C}$ for $24 \mathrm{~h}$ ]. EDS data of $\mathrm{CaOx}$ crystals obtained with (a) 0 (control), (b) 100, (c, d) 500, and (e, f) $1000 \mathrm{mg} / \mathrm{L}$ of 5 . The colors assigned to each element were arbitrarily chosen in the EDS measurements.

the $\mathrm{CaOx}$ crystal surface was stronger at higher polymer concentrations. At a concentration of $1000 \mathrm{mg} / \mathrm{L}$, the $\mathrm{Ca} / \mathrm{Si}$ ratios on the surface of COM and COD phases were 20.5 and 88.5 , respectively. In addition, a screening of the Si content (Supporting Information SI-1) and an elemental mapping of the $\mathrm{Si}, \mathrm{Ca}, \mathrm{C}, \mathrm{O}$ atoms on the $\mathrm{CaOx}$ surface (Supporting Information SI-2), which served as a semiquantitative surface determination by EDS, showed a homogeneous distribution of $\mathrm{Si}$ atoms in the range 1.23-1.51 wt.- $\%$. The relative amounts of $\mathrm{Si}$ atoms on the surface of $\mathrm{CaOx}$ crystals depended on the concentration of $\mathbf{5}$ used as a crystallization additive in the selective nucleation of $\mathrm{CaOx}$. Therefore, the $\mathrm{Ca}^{2+}$ concentration on the $\mathrm{CaOx}$ surface is regulated by the selective distribution of $\mathrm{Si}$ atoms from $\mathbf{5}$.
Because of the low amount of $\mathbf{5}$ required to alter the crystal morphology, we suggest that this polymer adsorbs preferentially on the $\mathrm{CaOx}$ crystal face and causes a morphogenetic effect. A similar mechanism has been reported for polyvinyl sulfonic acid (PVSA) as a synthetic polymer template, which inhibits the nucleation and crystal growth of $\mathrm{CaOx} .{ }^{[41]}$ We believe that the functionalized polymer 5 adsorbs onto specific crystal surfaces, acting as modulator of growth and exhibiting stereochemical recognition for certain faces of the crystal, thus, constituting an obstacle for propagating steps that lead to further crystal growth. ${ }^{[42,43]}$ The stabilization of COD crystals was achieved by using $50 \mathrm{mg} / \mathrm{L}$ of PVSA. There was also an outgrowth of COD along the $\{001\}$ direction, which resulted in elongated crys- 
tals and the development of $\{100\}$ crystal faces. We were unable to find this growth behavior under our crystallization conditions.

$\mathrm{UV} / \mathrm{Vis}$ spectroscopic kinetic measurements were performed to study the crystallization behavior in the presence of 5 (Figure 6). The change of absorbance implies an increase of optical density as a function of time, which indicates the formation of new particles formation, that is, crystal nucleation. When the optical density decreases, no new particles form because of crystal aggregation. ${ }^{[30]}$ This behavior shows the equilibrium between nucleation and aggregation. The samples showed a peak pattern between 2 and 10 min after the beginning of the reaction. This can be explained by the nucleation-aggregation borderline. However, when the concentration of $\mathbf{5}$ increases, the absorbance decreases, which suggests that the nucleation time extends beyond $20 \mathrm{~min}$. Additives with a large number of anionic groups increase the ionic strength, and interactions with positively charged ions $\left(\mathrm{Ca}^{2+}\right)$ can occur. This leads to a faster absorption of the inhibitors into crystal nuclei, which remain unstable and decay through dissolution. Consequently, the inhibitor is released and available to bind other newly formed nuclei. Finally, most of the growth sites are blocked by the anionic groups of the polymer backbone, but some sites remain free to develop, which results in a slow growth rate of the $\mathrm{CaOx}$ crystals. Thus, the crystalline growth beyond a critical size is hampered, and the nucleation period is prolonged.

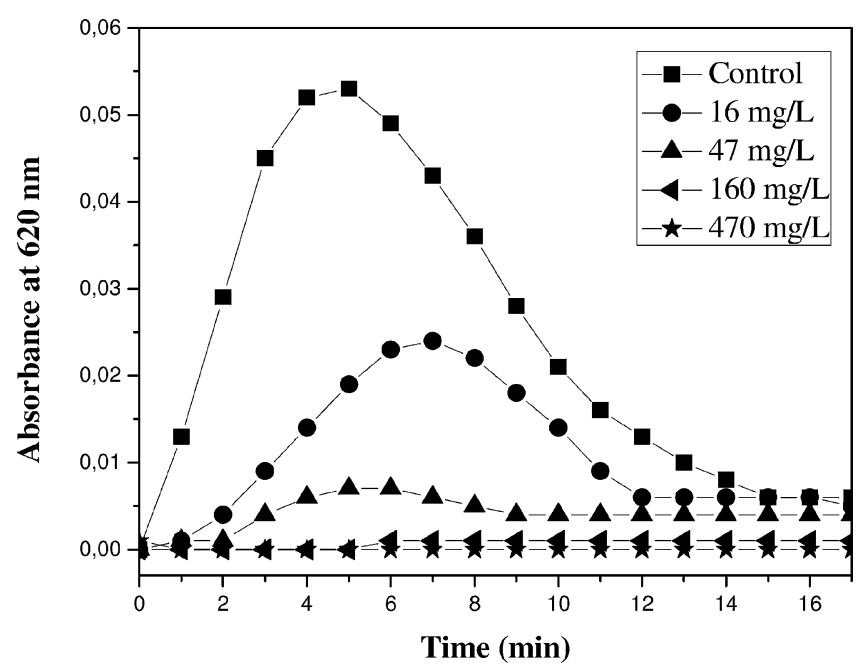

Figure 6. UV/Vis absorption spectra of $\mathrm{CaOx}$ crystals formed in presence of 5. Kinetic measurements were performed at $620 \mathrm{~nm}$ during the first 20 min upon initiation of the crystallization reactions. The concentrations of 5 were 0 (control), 16, 47, 160, and $470 \mathrm{mg} / \mathrm{L}$.

The above results are supported by zeta-potential measurements performed on the surfaces of $\mathrm{CaOx}$ crystals formed in the presence of $0,100,500$, and $1000 \mathrm{mg} / \mathrm{L}$ of 5 as an additive (Figure 7). These results show that the charge density on the crystal surface increases and reaches negative values from -5.27 to $-64.30 \mathrm{mV}$, as the concentration of $\mathbf{5}$ increases. Scurr et al. ${ }^{[44]}$ have reported that GAGs, which adhere reversibly to the surface of $\mathrm{CaOx}$ crystals, inhibited the growth and aggregation of crystals by lowering the zeta potential of the crystal surface and strengthening the electrical repulsive force among the crystals. It has also been reported that the strength of the inhibitory effect of sulfated polysaccharides may depend on their capacity to retain negative charge density or on the number of sulfate ions as well as on the distance between sulfate groups in these molecules. $^{[45]}$
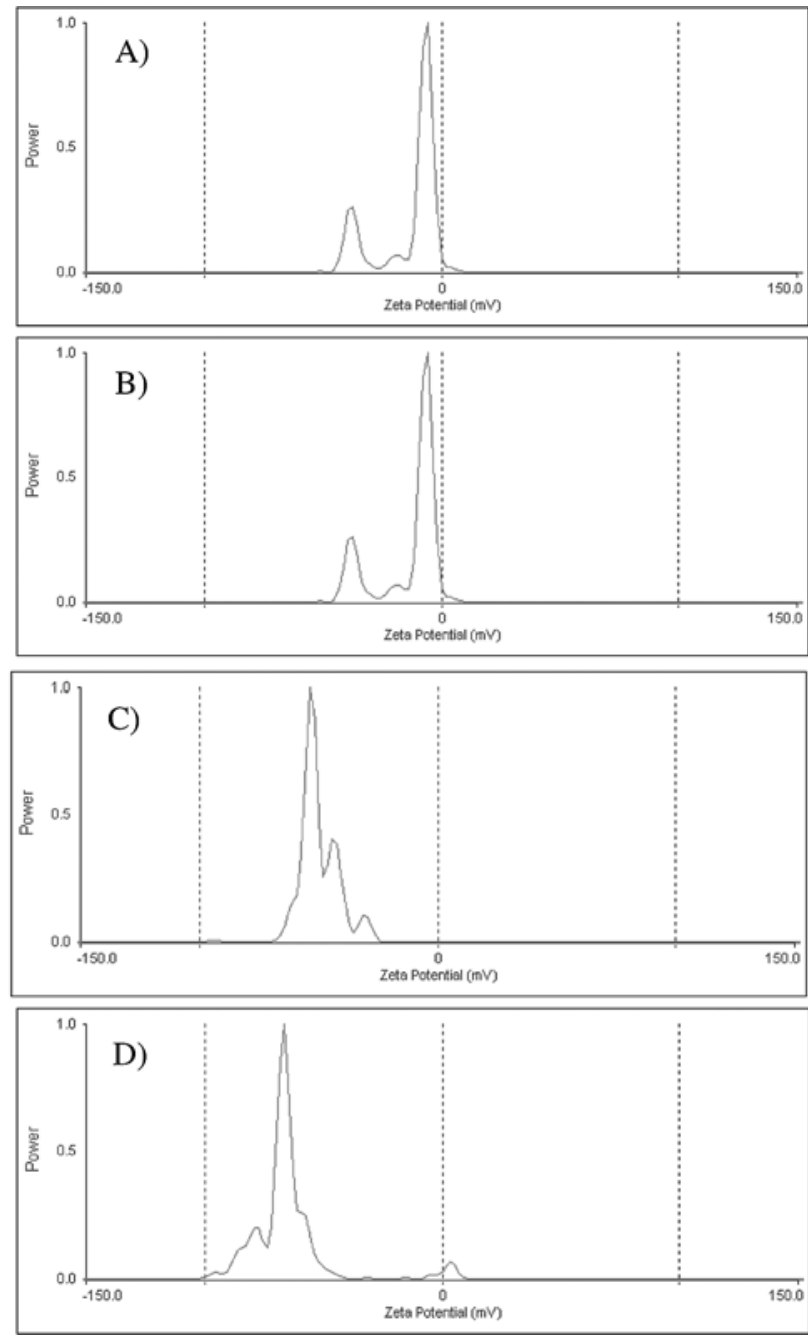

Figure 7. Zeta-potential measurements on the surface of $\mathrm{CaOx}$ crystals formed in presence of $\mathbf{5}$. The concentrations of $\mathbf{5}$ were (a) 0 (control), (b) 100, (c) 500, and (d) $1000 \mathrm{mg} / \mathrm{L}$.

For procedure B (Table 1), Figure 8 shows the SEM images of $\mathrm{CaOx}$ crystals nucleated in the presence of $\mathbf{5}$ at $20^{\circ} \mathrm{C}$ for $24 \mathrm{~h}$. Figure 8a shows COM crystals formed without 5. However, in Figure 8b, star-shaped COD and control crystals were formed when $16 \mathrm{mg} / \mathrm{L}$ of $\mathbf{5}$ was used. Clearly abundant and more defined star-shaped COD crystals were formed when the concentration of $\mathbf{5}$ was increased from 47 to $160 \mathrm{mg} / \mathrm{L}$ (Figures $8 \mathrm{c}$ and $\mathrm{d}$ ). Also, bipyramidal and plane multi-laminar circular crystals were formed (insert in Figure 8c). SEM results showed that at a concentration of $470 \mathrm{mg} / \mathrm{L}$ of $\mathbf{5}$, the amount of COD crystals decreased, and they formed irregular crystal agglomerates (Figure 8e). 

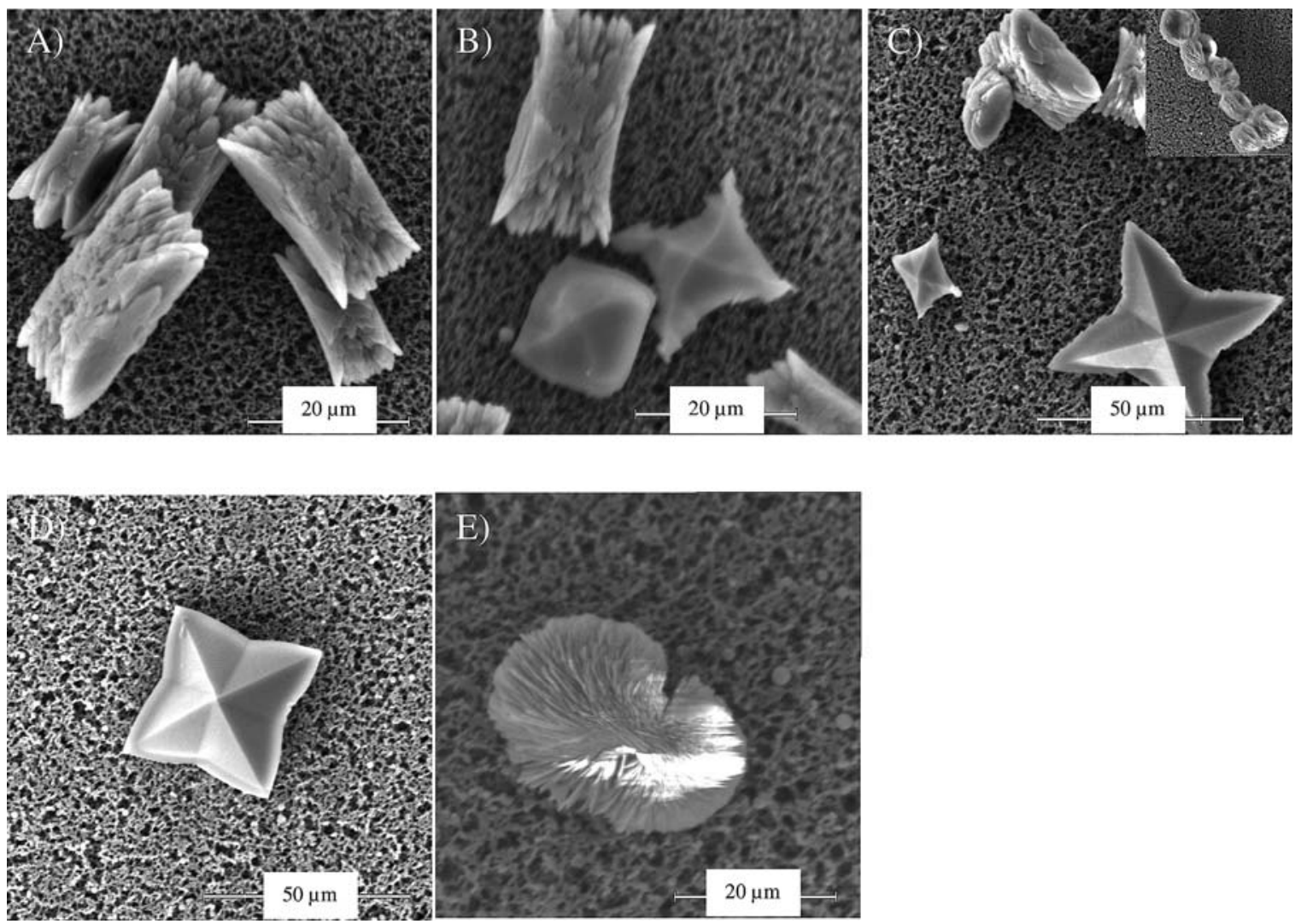

Figure 8. SEM images of $\mathrm{CaOx}$ crystals obtained with procedure $\mathrm{B}\left(\mathrm{CaCl}_{2}\right.$ and $\mathrm{Na}_{2} \mathrm{C}_{2} \mathrm{O}_{4}$ at $20{ }^{\circ} \mathrm{C}$ for $24 \mathrm{~h}$ ) and (a) 0 (control), (b) 16 , (c) 47 , (d) 160 , and (e) $470 \mathrm{mg} / \mathrm{L}$ of 5 .

Optical, fluorescent, and SEM-EDS images of $\mathrm{CaOx}$ crystals nucleated in the presence of fluorescent $\mathbf{5}$ at $20^{\circ} \mathrm{C}$ for $24 \mathrm{~h}$ are shown in Figure $9 \mathrm{a}-\mathrm{c}$. We found fluorescent $\mathrm{CaOx}$ crystals when 5 labeled with fluorescein-5-thiosemicarbazide (5-FTSC) was used. These results allowed us to prove the effective labeling of 5 with 5-FTSC and to demonstrate the adsorption of the fluorescent additive onto the surface of $\mathrm{CaOx}$ crystals. The use of fluorescent $\mathbf{5}$ as an additive induced the formation of rounded and truncated $\mathrm{CaOx}$ crystals, and 5 was included into the $\mathrm{CaOx}$ lattice. The EDS analysis (Figure 9c) showed the Si atoms and the constitutive elements $\mathrm{Ca}, \mathrm{C}$, and $\mathrm{O}$ on the surface of the $\mathrm{CaOx}$ crystals, demonstrating the presence of the polymeric additive on the crystal surface. The use of 5-FTSC, which is able to bind to various anionic and carbonyl groups, such as carboxylic acids, aldehydes, and ketones, represents a new strategy to study the effect of polymeric additives on the $\mathrm{CaOx}$ crystals. ${ }^{[46]}$ We suggest that there was a high selective tropism of the fluorescent 5 incorporated in COM in comparison to COD. COM exhibited a higher fluorescence level than COD. The binding capacity of 5-FTSC to $\mathbf{5}$ may constitute a useful strategy for molecular visualization of adsorbed additives on the surface of $\mathrm{CaOx}$. Taller et al. quantified the adsorption of protein and acid-rich additives, such as OPN, polyD, and poly-L-glutamate (polyE), to $\mathrm{COM}$ crystal faces and interfacial edges by using the fluorescent dye AlexaFluor-488. ${ }^{[3]}$ They found that OPN adsorbs with high specificity to the edges between $\{100\}$ and
$\{121\}$ faces of COM and much less to $\{100\},\{121\}$, or $\{010\}$ faces.
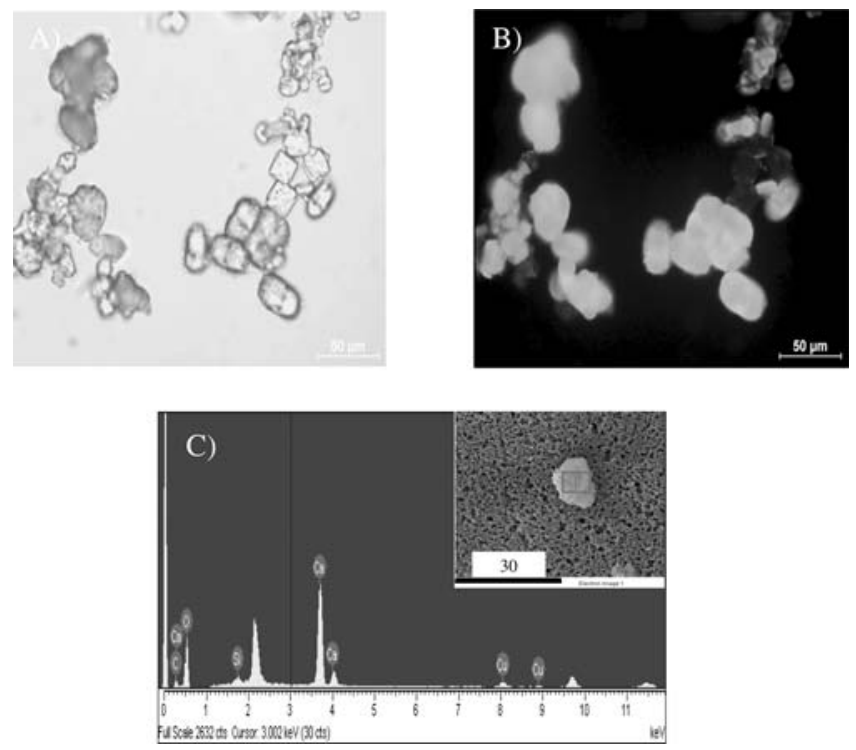

Figure 9. Optical, fluorescent, and SEM-EDS images of $\mathrm{CaOx}$ crystals labeled with 5 FTSC and obtained in the presence of 5 by using procedure $\mathrm{B}\left(\mathrm{CaCl}_{2}\right.$ and sodium oxalate at $20^{\circ} \mathrm{C}$ for $\left.24 \mathrm{~h}\right)$. Optical images of $\mathrm{CaOx}$ crystals obtained in the presence of 5 $(160 \mathrm{mg} / \mathrm{L})$ in (a) optical mode $(\times 40)$ and (b) fluorescence mode $(\times 40)$. SEM-EDS data (c) of $\mathrm{CaOx}$ crystals obtained with 5 ( $470 \mathrm{mg} / \mathrm{L})$, showing the presence of $\mathrm{Si}$ atoms. 


\section{Conclusions}

This work demonstrates that sulfonated polymethylsiloxanes, used as an additive in the in vitro crystallization of $\mathrm{CaOx}$, can modify the morphology, crystal type, and chemical composition of $\mathrm{CaOx}$ crystals. The sulfonic groups and the polymer concentration of $\mathbf{5}$ seem to be crucial during the nucleation and growth of $\mathrm{CaOx}$ crystals harvested under different conditions. The $\mathrm{CaOx}$ crystals formed in the presence of $\mathbf{5}$ are coincident with at least two crystal types, which are clearly detectable and have different morphologies, and bipyramidal COD crystals were stabilized in all crystallization procedures. The effect of $\mathbf{5}$ could be explained by its adsorption onto active growth sites of $\mathrm{CaOx}$ crystals. EDS and XRD techniques allowed detecting the presence of $\mathrm{Si}$ atoms from $\mathbf{5}$, which is adsorbed on the $\mathrm{CaOx}$ surfaces, where it acts as a stereochemical modulator of crystal growth. XRD data revealed characteristic diffraction patterns corresponding to COM and COD crystals. In summary, the use of anionic functionalized polymethylsiloxane is a viable approach for studying various aspects of biomineralization, which includes the production of controlled morphologies and the selective formation of specific crystal types of $\mathrm{CaOx}$.

\section{Experimental Section}

Materials: Poly(dimethylsiloxane-co-hydrogenmethylsiloxane) (PDMS-co-PHMS) (1), triflic acid, styrene, sulfuric acid, toluene, and methanol were used for the preparation of $\mathrm{SO}_{3} \mathrm{H}$-PMS (5). Dicyclopentadienyl(chlorido)platinum(II) $\left(\mathrm{Cp}_{2} \mathrm{PtCl}_{2}\right)$ was used as a catalyst in the hydrosilylation reaction. Toluene and dichloromethane were purified by heating it at reflux in the presence of lithium aluminum hydride and $\mathrm{K} / \mathrm{Na}$, respectively, for $72 \mathrm{~h}$ and distilled under argon. Calcium chloride $\left(\mathrm{CaCl}_{2}\right)$, calcium nitrate tetrahydrate $\left[\mathrm{Ca}\left(\mathrm{NO}_{3}\right)_{2} \cdot 4 \mathrm{H}_{2} \mathrm{O}\right]$, sodium acetate $\left(\mathrm{CH}_{3} \mathrm{CO}_{2} \mathrm{Na}\right)$, sodium chloride $(\mathrm{NaCl})$, sodium oxalate $\left(\mathrm{Na}_{2} \mathrm{C}_{2} \mathrm{O}_{4}\right)$ and $\mathbf{5}$ were used for in vitro $\mathrm{CaOx}$ crystallizations. In general, for the preparation of all solutions, reagents of the highest available grade were used. For the solutions involved in the $\mathrm{CaOx}$ crystallization distilled water was obtained from capsule filters with $0.2 \mu \mathrm{m}$ flow (U.S. Filter), and furthermore, ultra-pure water $(18.2 \mathrm{M} \Omega$ ) was obtained from the LaboStar $^{\mathrm{TM}}$ 4-DI/UV water system.

Synthesis and Characterization of PDMS-co-PHMS: Starting copolymer 1 was synthesized through cationic ring opening polymerization by using 2,2,4,4,6,6,8,8-octamethylcyclosiloxane $\left(\mathrm{D}_{4}\right)$ and 1,3,5,7-tetramethylcyclotetrasiloxane $\left(\mathrm{D}_{4}{ }^{\mathrm{H}}\right)$ as cyclic monomers at $30^{\circ} \mathrm{C}$ for $5 \mathrm{~d}$. Triflic acid $\left(2.5 \times 10^{-3} \mathrm{~mol} / \mathrm{L}\right)$ was used as a cationic initiator. The polymerization reaction was carried out under anhydrous conditions. The mixture was refluxed under argon with agitation until both FTIR and ${ }^{1} \mathrm{H}$ NMR spectra showed that the hydrosilylation reaction was completed. ${ }^{[47]}$ The polymerization was stopped by adding a stoichiometric amount of pyridine. The molecular weight $\left(M_{\mathrm{w}}\right)$ determination of $\mathbf{1}$ was carried out by gel permeation chromatography (GPC) in THF at room temperature by using PSS-Win GPC-PSS and RI ERC 7512 refractive-index detectors.

Synthesis of Sulfonated Polymethylsiloxane as Template: The preparation of $\mathbf{5}$ involved two stages (see Figure 1). The starting material $\mathbf{1}$ was modified through a hydrosilylation reaction and a subsequent sulfonation to obtain $\mathbf{5}$. For the hydrosilylation of $\mathbf{1}$, styrene ( $20 \mathrm{~mol}-\%$ excess with respect to 1) was dissolved in a toluene $(100 \mathrm{~mL})$ containing a precise amount of $\mathbf{1}$. Then a solution of $\mathrm{Cp}_{2} \mathrm{PtCl}_{2}(100 \mu \mathrm{L})$ solution was added, and the mixture was heated to $85^{\circ} \mathrm{C}$ under argon, as reported previously. ${ }^{[33,47-50]}$ The excess of solvent and unreacted monomer were then removed. Figure 1a shows the synthesis of $\mathbf{3}$ by the modification of $\mathbf{1}$ with styrene through a hydrosilylation reaction; $\mathbf{3}$ was then dried in vacuum at $40{ }^{\circ} \mathrm{C}$ for $72 \mathrm{~h}$. After that, 3 was modified with a stoichiometric amount of sulfonic groups by dissolving both $\mathbf{3}$ and sulfonic acid in dichloromethane at room temperature overnight. Then, the reaction temperature was increased to $80^{\circ} \mathrm{C}$, and the mixture was incubated for $2 \mathrm{~h}$. The sulfonic acid used was previously dried with $\mathrm{CaH}_{2} ; \mathbf{5}$ was obtained by evaporation of dichloromethane. It was washed with methanol and dried in vacuum at $40^{\circ} \mathrm{C}$ for $2 \mathrm{~h}$. The yields for the hydrosilylation and sulfonation reactions were $>95 \%$.

In Vitro Calcium Oxalate Crystallization Experiments: In vitro crystallization of $\mathrm{CaOx}$ was performed by using three procedures: $\mathrm{A}, \mathrm{B}$, and $\mathrm{C}$. They differ in the reagents used $\left[\mathrm{CaCl}_{2}\right.$ or $\mathrm{Ca}-$ $\left(\mathrm{NO}_{3}\right)_{2} \cdot 4 \mathrm{H}_{2} \mathrm{O}$ and $\mathrm{Na}_{2} \mathrm{C}_{2} \mathrm{O}_{4}$ ], in the $\mathrm{Ca}$ /oxalate ratio, and in the concentration of 5 (Table 1). The reactants were $\mathrm{CaCl}_{2}$ and $\mathrm{Na}_{2} \mathrm{C}_{2} \mathrm{O}_{4}$ for procedures $\mathrm{A}$ and $\mathrm{C}$, and $\mathrm{Ca}\left(\mathrm{NO}_{3}\right)_{2} \cdot 4 \mathrm{H}_{2} \mathrm{O}$ and $\mathrm{Na}_{2} \mathrm{C}_{2} \mathrm{O}_{4}$ were used for procedure $\mathrm{B}$. The reactants were used in a 1:1 ratio in procedures $\mathrm{A}$ and $\mathrm{B}$ [A: $2 \mathrm{mM} \mathrm{Ca}\left(\mathrm{NO}_{3}\right)_{2} \cdot 4 \mathrm{H}_{2} \mathrm{O}$ and $2 \mathrm{mM} \mathrm{Na}_{2} \mathrm{C}_{2} \mathrm{O}_{4}$ solutions; $\mathrm{B}$ : $15 \mathrm{~mL}$ of $4 \mathrm{~mm} \mathrm{CaCl} \mathrm{Ca}_{2}$ and $15 \mathrm{~mL}$ of $4 \mathrm{~mm} \mathrm{Na}_{2} \mathrm{C}_{2} \mathrm{O}_{4}$ ]. For procedure $\mathrm{C}$, a ratio of $10: 1$ was used $(15 \mathrm{~mL}$ of $10 \mathrm{mM} \mathrm{CaCl}_{2}$ and $15 \mathrm{~mL}$ of $1 \mathrm{mM} \mathrm{Na}_{2} \mathrm{C}_{2} \mathrm{O}_{4}$ ). In the case of procedure $\mathrm{A}$, the reactant solutions were kept at a constant $\mathrm{pH}$ of 6.7 at $37^{\circ} \mathrm{C} \cdot{ }^{[34,35]} \mathrm{In}$ all crystallization procedures, control experiments were performed without polymer. For procedures A and B, the crystallizations of $\mathrm{CaOx}$ with $\mathbf{5}$ were carried out in the concentration range $0.64-640 \mathrm{mg} / \mathrm{L}$ and $100-1000 \mathrm{mg} / \mathrm{L}$ with $\mathrm{CaCl}_{2}$ and $\mathrm{Ca}\left(\mathrm{NO}_{3}\right)_{2} \cdot 4 \mathrm{H}_{2} \mathrm{O}$, respectively. For procedure $\mathrm{C}$, both polymeric additives were tested at concentrations of $16-470 \mathrm{mg} / \mathrm{L}$. In all procedures, each solution $(150 \mu \mathrm{L})$ was introduced into a Falcon tube; then, solutions with suitable $\mathrm{Ca}$ /oxalate ratios were added at $20^{\circ} \mathrm{C}$ and left to stand quiescent for $24 \mathrm{~h}$. After that, the mixtures were filtered by using GS cellulose ester membranes having $0.22 \mu \mathrm{m}$ pores and $25 \mathrm{~mm}$ diameter, and the solid residues were dried at room temperature for $24 \mathrm{~h}$. Fluorescein-5-thiosemicarbazide (5FTSC, Invitrogen ${ }^{\circledR}$ ) was used as a fluorescent molecule. 5-FTSC was attached to the anionic groups of $\mathbf{5}$ by an electrostatic coupling reaction. Here, solutions (500 $\mu \mathrm{L}$ each) containing $5(470 \mathrm{mg} / \mathrm{L})$ and 5 -FTSC $(6.3 \mathrm{mg} / \mathrm{L})$ were prepared. All solutions were incubated at $4{ }^{\circ} \mathrm{C}$ before use.

Polymer and Crystal Characterization: Fourier transform infrared spectroscopy (FTIR) was used to evaluate the structures of $\mathbf{1}, \mathbf{3}$, and 5. FTIR spectra were taken by using an Interspectrum Interspec $\mathrm{p} / \mathrm{n}$ 200-X spectrometer. NMR $\left({ }^{1} \mathrm{H},{ }^{29} \mathrm{Si}\right)$ spectra of $\mathbf{1}$ and 5 were measured with a Bruker $250 \mathrm{MHz}$ spectrometer. ${ }^{[47]}$ Scanning electron microscopy (SEM) was performed with a Tesla BS 343A microscope. Energy-dispersive X-ray spectroscopy (EDS) of $\mathbf{1}$ and $\mathrm{CaOx}$ crystals was performed by using a SEM LEO 1420VP scanning electron microscope equipped with a dispositive for surface element microanalysis and a linear profile at $15 \mathrm{kV}$. SEM-EDS micrographs of $\mathrm{CaOx}$ crystals were captured by using a Hitachi TM3000 tabletop microscope (Hitachi High Tech) coupled with an energy-dispersive X-ray microanalysis (EDS) spectrometer Quantax 70 (Bruker, Germany) and equipped with a high-sensitivity semiconductor BSE detector. The morphologies and EDS studies of $\mathrm{CaOx}$ crystals were carried out by using "analysis" as observation condition and the "charge-up reduction mode" as observation mode. The weight percent (wt.-\%) concentrations of individual 
elements at the crystal surface were calculated automatically by the EDS software. Images of fluorescent $\mathbf{5}$ and of fluorescent-labeled $\mathrm{CaOx}$ crystals were taken with a Nikon Eclipse E-600 connected to a computer with morphometric software (Image Pro-Plus, Media Cybernetics, USA). Optical images were obtained by using a digital camera at a $\times 40$ magnification and an exposure time of $20 \mathrm{~ms}$ to $2 \mathrm{~s}$ with a resolution of $2560 \times 1920$ pixels. Powder X-ray diffraction (PXRD) was performed by using a Siemens D-5000X X-ray diffractometer with $\mathrm{Cu}-K_{\alpha}$ radiation (graphite monochromator) and an ENRAF Nonius FR 590. The crystal structure of $\mathrm{CaOx}$ was determined by using $\mathrm{Cu}-K_{\alpha}$ radiation $(40 \mathrm{kV})$, steps of $0.2^{\circ}$, and the geometric Bragg-Brentano $(\theta-\theta)$ scanning mode with an

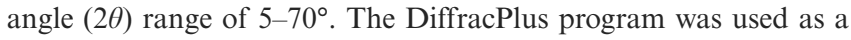
data-control software. For UV analysis, crystallization procedure $\mathrm{C}$ was used. Aqueous stock solutions of $\mathrm{CaCl}_{2}(10 \mathrm{mmol} / \mathrm{L})$ and $\mathrm{Na}_{2} \mathrm{C}_{2} \mathrm{O}_{4}(1 \mathrm{mmol} / \mathrm{L})$ were prepared. Here, $1 \mathrm{~mL}$ of each solution and $200 \mu \mathrm{L}$ aliquots of $16,47,160$, and $470 \mathrm{mg} / \mathrm{L}$ solutions of 5 were mixed in square polystyrene cuvettes $(10 \mathrm{~mm})$, and the optical density of the crystals was measured immediately in a UV/Vis spectrophotometer UV-2601 (Raleigh, China). The UV measurements were performed at $1 \mathrm{~min}$ intervals over $20 \mathrm{~min}$ at $620 \mathrm{~nm} \cdot{ }^{[30]}$ Charge density determinations of $\mathrm{CaOx}$ crystals were performed by using the zeta potential and dynamic light scattering. The zeta-potential measurements on $\mathrm{CaOx}$ crystals were performed in the presence of $5(100-1000 \mathrm{mg} / \mathrm{L})$ by using a Zeta Plus analyzer (Brookhaven Instruments). The zeta potential parameters were: simple count rate $192-374 \mathrm{kcps}$, sampling time $256 \mu \mathrm{s}$, wavelength $660 \mathrm{~nm}$, current $2.07-4.45 \mathrm{~mA}$, and electric field $13.62-14.19 \mathrm{~V} / \mathrm{cm}$.

\section{Acknowledgments}

This work was supported by the Fondo Nacional de Desarrollo Científico y Tecnológico through the project FONDECYT 1110194 and partially supported by the Fondo de Financiamiento de Centros de Investigación en Áreas Prioritarias through the projects Fondap 15130011, Conicyt-Mincyt PCCI 12038, 12039, and U-Redes Program, and by the Vicerrectoría de Investigación y Desarrollo (VID), Universidad de Chile. P. V.-Q. is grateful for a CONICYT fellowship.

[1] R. B. Doddametikurke, C. S. Biyani, A. J. Browning, J. J. Cartledge, EAU-EBU Update Ser. 2007, 5, 126-136.

[2] F. Coe, A. Evan, E. Worcester, J. Clin. Invest. 2005, 115, 25982608.

[3] A. Taller, B. Grohe, K. A. Rogers, H. A. Goldberg, G. K. Hunter, Biophys. J. 2007, 93, 1768-1777.

[4] J. M. Ouyang, M. Wang, J. Tan, Mater. Sci. Eng. C 2010, 30, 1022-1029.

[5] C. P. East, A. D. Wallace, A. Al-Hamzah, W. O. S. Doherty, C. M. Fellows, J. Appl. Polym. Sci. 2009, 112, 2127-2135.

[6] A. Millan, Cryst. Growth Des. 2001, 1, 245-254.

[7] J. M. Ouyang, D. Z. Chen, J. P. Zhong, Mol. Cryst. Liq. Cryst. 2004, 420, 91-96.

[8] H. Peng, J. M. Ouyang, X. Q. Yao, R. E. Yang, Int. J. Nanomed. 2012, 7, 4727-4737.

[9] Y. M. Michelacci, R. Q. Glashan, N. Schor, Kidney Int. 1989, 36, 1022-1028.

[10] H. Sidhu, A. K. Hemal, S. K. Thind, R. Nath, S. Vaidyanathan, Eur. Urol. 1989, 16, 45-47.

[11] A. H. Angell, M. I. Resnick, J. Urol. 1989, 141, 1255-1258.
[12] A. Hesse, H. Wuzel, W. Vahlensieck, Am. J. Kidney Dis. 1991, $17,414-419$

[13] K. Suzuki, R. L. Ryall, Brit. J. Urol. 1996, 58, 15-21.

[14] B. Fellstrom, B. G. Danielson, S. L. Ljunghall, B. Wilkstrom, Clin. Chim. Acta 1986, 158, 229-235.

[15] Y. M. Michelacci, M. A. Boim, C. T. Bergamaschi, R. M. Rovigatti, N. Schor, Clin. Chim. Acta 1992, 208, 1-8.

[16] J. Yu, H. Tang, B. Cheng, X. Zhao, J. Solid State Chem. 2004, 177, 3368-3374.

[17] O. W. Moe, Lancet 2006, 367, 333-344.

[18] B. Akin, M. Oner, Y. Bayram, K. D. Demadis, Cryst. Growth Des. 2008, 8, 1997-2005.

[19] C. Escobar, A. Neira-Carrillo, M. S. Fernández, J. L. Arias, in Biomineralization - from Paleontology to Materials Science (Eds.: J. L. Arias, M. S. Fernandez), Editorial Universitaria, Santiago, Chile, 2007, pp. 343-357.

[20] Y. C. Chien, D. L. Masica, J. J. Gray, S. Nquyen, H. Vali, M. D. McKee, J. Biol. Chem. 2009, 284, 23491-23501.

[21] A. Xie, Y. Shen, D. Ma, F. Huang, L. Qiu, S. Li, L. Chen, Cryst. Res. Technol. 2007, 42, 667-672.

[22] J. J. De Yoreo, S. R. Qiu, J. R. Hoyer, Am. J. Physiol.: Renal, Fluid Electrolyte Physiol. 2006, 291, F1123-F1132.

[23] S. R. Qiu, A. Wierzbicki, C. A. Orme, A. M. Cody, J. R. Hoyer, G. H. Nancollas, S. Zepeda, J. J. De Yoreo, Proc. Natl. Acad. Sci. USA 2004, 101, 1811-1815.

[24] J. A. Jesson, M. D. Ward, Elements 2007, 3, 415-421.

[25] S. R. Qiu, A. Wierzbicki, E. A. Salter, S. Zepeda, C. A. Orme, J. R. Hoyer, G. H. Nancollas, A. M. Cody, J. J. De Yoreo, J. Am. Chem. Soc. 2005, 127, 9036-9044.

[26] I. O. Benitez, D. R. Talham, Langmuir 2004, 20, 8287-8293.

[27] I. O. Benitez, D. R. Talham, J. Am. Chem. Soc. 2005, 127, $2814-2815$

[28] Y. H. Shen, W. J. Yue, A. J. Xie, Z. Q. Lin, F. Z. Huang, Colloids Surf. A 2004, 234, 35-41.

[29] B. Akin, M. Öner, Y. Bayram, K. D. Demadis, Cryst. Growth Des. 2008, 8, 1997-2005.

[30] S. Kulaksizoglu, M. Sofikerim, C. Cevik, Int. J. Urol. 2007, 14, 214-218.

[31] A. Djelloul, A. Driouch, F. Taleb, Z. Kaid-Omar, A. Semmoud, A. Addou, Asia-Pac. J. Chem. Eng. 2012, 7, 328-336.

[32] M. A. Brook, Silicon in Organic, Organometallic and Polymer Chemistry, John Wiley \& Sons Inc., New York, 2000, vol. 9, pp. 256-308.

[33] A. Neira-Carrillo, P. Vásquez-Quitral, M. Yazdani-Pedram, J. L. Arias, Mol. Cryst. Liq. Cryst. 2010, 522, 7-17.

[34] B. Grohe, K. A. Rogers, H. A. Goldberg, G. K. Hunter, J. Cryst. Growth 2006, 295, 148-157.

[35] B. Grohe, A. Taller, P. L. Vincent, L. D. Tieu, K. A. Rogers, A. Heiss, E. S. SØrensen, S. Mittler, H. A. Goldberg, G. K. Hunter, Langmuir 2009, 25, 11635-11645.

[36] C. R. Martins, G. Ruggeri, M. A. Paoli, J. Braz. Chem. Soc. 2003, 14, 797-802.

[37] J. A. Wesson, E. M. Worcester, J. G. Kleinman, J. Urol. 2000, $163,1343-1348$

[38] A. Langdon, G. R. Wignall, K. Rogers, E. S. Sorensen, J. Denstedt, B. Grohe, H. A. Goldberg, G. K. Hunter, Calcif. Tissue Int. 2009, 84, 240-248.

[39] S. P. Deng, H. Zheng, J. M. Ouyang, Mater. Sci. Eng. C 2006, 26, 683-687.

[40] T. Jung, W. S. Kimb, C. K. Choi, J. Cryst. Growth 2005, 279, $154-162$.

[41] S. Kırboğa, M. Öner, Biointerfaces. 2010, 78, 357-362.

[42] I. Weissbuch, R. Popovitz-Biro, M. Lahav, L. Leiserowitz, Acta Crystallogr., Sect. B 1995, 51, 115-148.

[43] J. J. De Yoreo, P. Vekilov, "Principles of Crystal Nucleation and Growth" in Biomineralization (Eds: P. M. Dove, J. J. De Yoreo, S. Weiner), Mineralogical Society of America, Washington, DC, 2003, chapter 3, pp. 57-93.

[44] D. S. Scurr, W. G. Robertson, J. Urol. 1986, 136, 128-131. 
[45] E. R. Boevé, L. C. Cao, C. F. Verkoelen, J. C. Romijn, W. C. de Bruijin, F. H. Schroeder, World J. Urol. 1994, 12, 43-48.

[46] P. A. Paprica, A. Margaritis, N. O. Petersen, Bioconjugate Chem. 1992, 3, 32-36.

[47] A. Neira-Carrillo, R. K. Pai, M. S. Fernández, E. Carreño, P. Vásquez-Quitral, J. L. Arias, Colloid Polym. Sci. 2009, 287, 385-393.

[48] M. Rodríguez-Baeza, A. Neira-Carrillo, J. C. Aguilera, Polym. Bull. 2003, 50, 25-32.
[49] A. Neira-Carrillo, P. Vásquez-Quitral, M. Yazdani-Pedram, J. L. Arias, Eur. Polym. J. 2010, 46, 1184-1193.

[50] A. Neira-Carrillo, R. K. Pai, V. M. Fuenzalida, M. S. Fernández, J. Retuert, J. L. Arias, J. Chil. Chem. Soc. 2008, 53, 1469-1473. 